\title{
Ser do tempo em Bergson
}

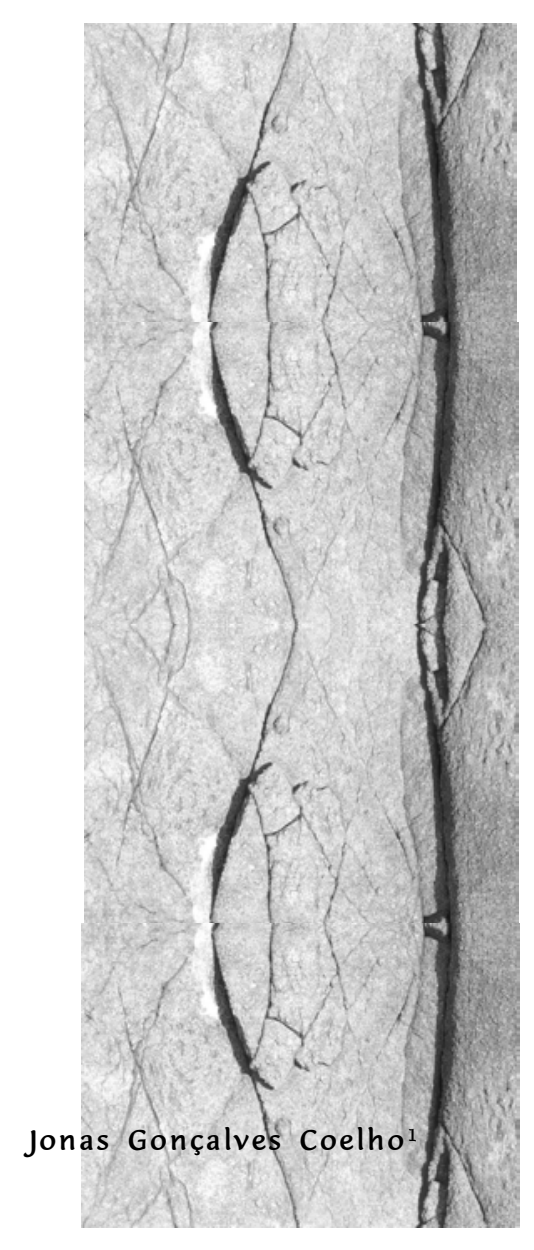

COELHO, J. G. Being and time in Bergson, Interface - Comunic., Saúde, Educ., v.8, n.15, p.233-46, mar/ago 2004.

We considered Bergson's duration concept. We intended to show that, according to Bergson, the time of philosophers and scientists is a fictitious time, a spatial scheme that hides the nature of real time, which cannot be separated from physical and psychological events. For Bergson, real time is succession, continuity, change, memory and creation.

KEY WORDS: Bergson; duration; time; space.

O artigo apresenta a concepção bergsoniana de duração. Pretende-se mostrar que, segundo Bergson, o tempo dos filósofos e cientistas é um tempo fictício, um esquema espacial que oculta a natureza do tempo real, o qual não pode ser separado dos acontecimentos físicos e psicológicos. Para Bergson, o tempo real é sucessão, continuidade, mudança, memória e criação.

PALAVRAS-CHAVE: Bergson; duração; tempo; espaço.

${ }^{1}$ Professor Assistente Doutor, Departamento de Ciências Humanas, Faculdade de Arquitetura, Artes e Comunicação, Unesp, Bauru, SP.
<jonas@faac.unesp.br>

Av. Siqueira Campos, 651, apto.91 A

Bairro Embaré - Santos, SP

$11.045-201$

Interface - Comunic., Saúde, Educ., v.8, n.15, p.233-46, mar/ago 2004 
COELHO, J. G.

Voltamos, pois, sempre ao mesmo ponto: há só um Tempo real e os
outros são fictícios. Que é em efeito um Tempo real senão um
Tempo vivido ou que poderia o ser? Que é um Tempo irreal, auxiliar,
fictício, senão aquele que não poderia ser vivido efetivamente por
nada nem por ninguém? (Bergson, 1972, p.130)

\section{Introdução}

Por definição, o passado é o que não é mais, o futuro, o que ainda não é, e o presente é o que é. Mas o instante presente, quando percebido, já passou. Como compreender a relação entre passado, presente e futuro? O que é o tempo? Trataremos dessas questões a partir do pensamento do filósofo francês Henri Bergson (1859-1941).

O tempo constitui tema fundamental do pensamento desse autor. Sua filosofia é uma filosofia do tempo. Bergson critica o pensamento filosófico e científico por desconsiderar o tempo real, cuja natureza se propõe a explicitar ao longo de suas obras. O tempo dos filósofos e cientistas seria um tempo esquemático e espacial, incompatível com o tempo que é o próprio tecido do real, ou seja, o tempo que Bergson define como sucessão, continuidade, mudança, memória e criação.

Para tratar desses aspectos do pensamento de Bergson, dividiremos nossa exposição em duas partes. Na primeira, apresentaremos a crítica bergsoniana à concepção dominante do tempo, daquilo que, para ele, o tempo não é. A seguir, trataremos da concepção bergsoniana do tempo real.

\section{Tempo fictício}

\section{Parte I}

Consideremos, inicialmente, o tempo fictício, "aquele que não poderia ser vivido efetivamente por nada, nem por ninguém". Referindo-se no início da introdução de $O$ Pensamento e o movente ao seu percurso filosófico, Bergson diz ter procurado, desde o começo de suas investigações, algo que constatou estar ausente na filosofia: a precisão. Contra os sistemas filosóficos, cujas concepções seriam abstratas e vastas, Bergson procurava uma explicação "que aderisse ao seu objeto", que não deixasse "nenhum vazio, nenhum interstício onde uma outra explicação se pudesse alojar", enfim, uma explicação que "conviesse somente àquele objeto", que se prestasse "apenas àquela explicação". Relata, ainda, que se ligou em sua juventude à filosofia de Spencer, pois ela lhe pareceu ser uma exceção, já que "visava a modelar-se sobre as coisas, sobre o detalhe dos fatos". Mas havia no pensamento de Spencer um ponto fraco, o conhecimento insuficiente de mecânica, cujos conceitos fundamentais Bergson pretendia estudar em seu doutorado com o objetivo de completar e consolidar a obra de Spencer. Como afirmava Bergson em uma correspondência de 1903, foi esse interesse pela mecânica que o levou a se "ocupar da idéia de tempo", surpreendendose ao constatar que tanto a física quanto a matemática não se ocupavam do "tempo real", da "duração real" (1972, p.604), que o tempo de que elas tratavam era um tempo que "não servia para nada (...) não fazia nada"2 (Bergson, 1993a, p.102).

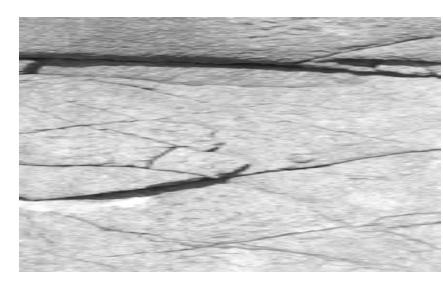

${ }^{2}$ Conforme um ensaio de 1930, "Le possible et le réel" 
O que significa a tese bergsoniana segundo a qual a física e a matemática tratavam de um tempo que não fazia nada, que não servia para nada? Se a física e a matemática não se ocupavam do tempo real, de que tempo se ocupavam?

Primeiro, a idéia de que o tempo dos físicos não faz nada, não serve para nada, está implicada na crença de que, se houvesse uma inteligência sobrehumana, ela seria capaz de calcular o futuro e o passado a partir dos elementos do presente. Em sua obra $A$ evolução criadora, Bergson cita três grandes representantes dessa hipótese: Laplace, Du Bois e Huxley.

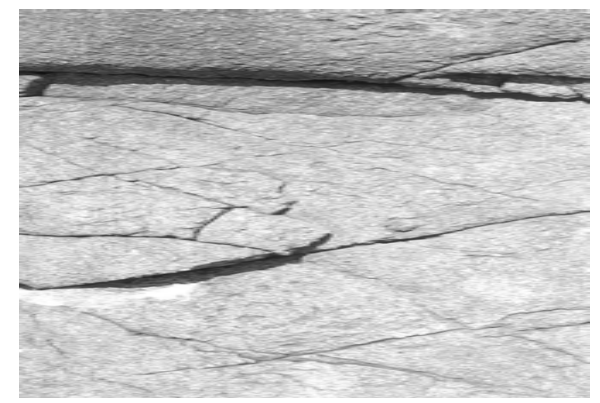

Laplace já a formulara com precisão: 'Uma inteligência que, em dado instante, conhecesse todas as forças de que é animada a natureza e a situação respectiva dos seres que a compõem, se fosse bastante grande para submeter esses dados à análise, abrangeria na mesma fórmula os movimentos dos maiores corpos do universo bem como os do átomo mais leve: nada seria incerto para essa inteligência, e tanto o futuro como o passado estariam diante de seus olhos.' E Du Bois-Reymond: 'Pode-se imaginar o conhecimento da natureza chegado a um ponto em que o processo universal do mundo fosse representado por uma fórmula matemática única, por um único imenso sistema de equações diferenciais simultâneas, donde se deduzisse, para cada momento, a posição, a direção e a velocidade de cada átomo do mundo.' Huxley, por sua vez, exprimiu sob forma ainda mais concreta a mesma idéia: 'Se a proposição fundamental da evolução for verdadeira, a saber, que o mundo inteiro, animado e inanimado, é o resultado da interação mútua, segundo leis definidas, das forças possuídas pelas moléculas de que a nebulosidade primitiva do universo era composta, então também é certo que o mundo atual repouse potencialmente no vapor cósmico, e que uma inteligência suficiente poderia, conhecendo as propriedades das moléculas desse vapor, predizer, por exemplo, o estado da fauna da Inglaterra em 1868, com tanta certeza quanto se diz do que acontecerá ao vapor da respiração num dia frio de inverno'. (Bergson, 1991, p.38)

Esses são exemplares de uma concepção abstrata do tempo, de acordo com a qual os fenômenos que se sucedem no mundo físico seguem uma ordem imutável e intemporal, em que a distinção entre passado, presente e futuro parece ilusória, considerando-se que passado e futuro poderiam, pelo menos em princípio, ser apreendidos no presente, estar diante dos olhos de um "superfísico". Trata-se de um tempo no qual a mesma causa sempre produz o mesmo efeito e é isso que torna possível o estabelecimento de leis que permitem a previsão, o cálculo antecipado dos fenômenos futuros que preexistiriam de certa forma à sua realização.

Além do mais, o tempo dos físicos e matemáticos é reversível, ou seja, as equações que descrevem os acontecimentos passados e futuros permaneceriam as mesmas ainda que os invertêssemos. 
COELHO, J. G.

As leis da dinâmica newtoniana não impõem nenhuma direção
privilegiada ao tempo: as equações que levam em consideração,
por exemplo, os movimentos dos planetas em torno do Sol
continuariam absolutamente imutáveis se o sentido do
movimento dos planetas se invertesse. (Piettre, 1997, p.60)

Esse tempo está dissociado do conteúdo dos sistemas considerados, que são como o abrir e o fechar de um leque: "O leque que se desdobra poderá abrir-se cada vez mais depressa e mesmo instantaneamente: ele mostrará sempre o mesmo desenho já inscrito na seda" (Bergson, 1993a, p.11). Assemelha-se ao desenrolar de um filme cinematográfico, já que a velocidade com que este é passado não modifica as imagens: "se ele se desenvolvesse a uma velocidade infinita, se o desenrolar (desta vez fora do aparelho) se tornasse instantâneo, seriam ainda as mesmas imagens" (Bergson, 1993a, p.9).

Para Bergson, o tempo dos físicos e matemáticos é um tempo espacializado, compreendido como uma linha imóvel, com o qual se pretende medir a duração das coisas. Utiliza-se essa linha imóvel para representar a sucessão múltipla de eventos. Tal representação do tempo envolve a idéia de multiplicidade e sua íntima relação com o espaço. Vejamos como se dá essa articulação entre multiplicidade e espaço.

A idéia de multiplicidade remete imediatamente à idéia de número. Trata-se de uma multiplicidade numérica. A idéia de número articula-se profundamente aos objetos materiais. Nós nos referimos a esses objetos como passíveis de ver e tocar e, para contá-los, precisamos representá-los ao mesmo tempo, reter a imagem de todos simultaneamente, $e$ isso só se torna possível no espaço. Bergson admite que se possa, por meio de algarismos ou palavras, imaginar ou pensar o número sem remeter à extensão, o que não é possível em uma representação intelectual, em que a imagem de extensão entra necessariamente. O número é o

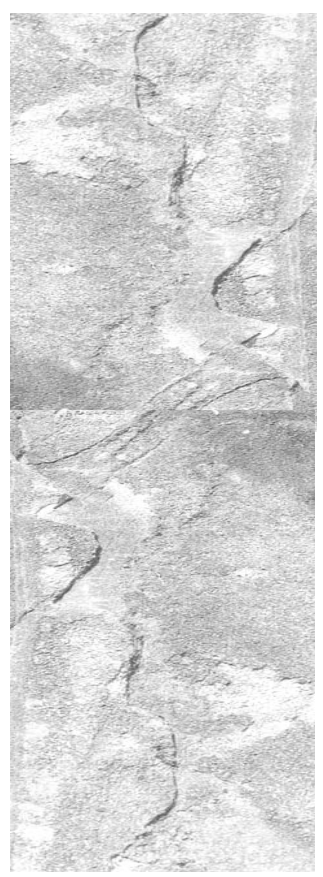
componente de uma multiplicidade que se pode contar isoladamente, uma coleção dessas unidades. Mas essas mesmas unidades que entram na composição da multiplicidade distinta pressupõem uma visão no espaço. Esta unidade corresponde a um ato simples do espírito que consiste em unir, e tal união só é possível se alguma multiplicidade lhe serve de matéria. As unidades são consideradas enquanto tais apenas provisoriamente, para compor-se com outras. Mas, ao considerá-las em si mesmas, elas poderiam ser divididas, possuindo, portanto, extensão:

é necessário distinguir entre a unidade em que se pensa e a unidade que coisificamos após nela termos pensado, assim como entre o número em vias de formação e o número uma vez formado. A unidade é irredutível enquanto nela se pensa, e o número é descontínuo enquanto se constrói; mas, quando se considera o número em estado de acabamento, objetiva-se: e é precisamente por isso que aparece, então, como indefinidamente divisível. (Bergson, 1988, p.62) 


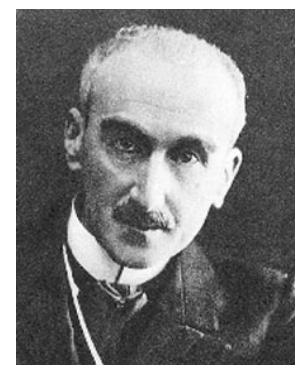

${ }^{3}$ Em uma conferência proferida em 1911, "La perception du changement".
Em decorrência da associação entre a idéia de número e os objetos materiais que se apresentam no espaço, nós podemos contá-los diretamente, pensando-os separadamente, de início, e simultaneamente, em seguida. Mas, quando se trata da sucessão múltipla dos eventos do mundo, só podemos contá-los por um processo de figuração simbólica, na qual intervém, necessariamente, o espaço. Tal figuração, que aparece inicialmente como uma representação da sucessão temporal, é, em última instância, espacial, ou seja, trata-se de uma temporalidade profundamente impregnada de espaço: ao falarmos do tempo, pensamos quase sempre em um meio homogêneo no qual os fatos se alinham, se justapõem, como no espaço, formando uma multiplicidade distinta.

\section{Parte II}

Essa espacialização do tempo pode ser constatada na representação da vida interior. Procurando saber o que é efetivamente a duração, como ela "apareceria a uma consciência que desejaria apenas vê-la sem medi-la, que a agarrasse sem imobilizá-la, que se tomaria a si mesma por objeto", Bergson (1993a, p.4) volta-se para o "domínio da vida interior" - metafísica e psicologia - que antes não lhe interessava. Assim, abandona seu projeto inicial de doutoramento, ou seja, o estudo dos conceitos fundamentais de mecânica, e se volta ao estudo da duração interior à qual ele se propõe a aplicar seu ideal de conhecimento preciso e imediato.

Ao voltar-se para a investigação do psicológico, Bergson diz $^{3}$ ter-se deparado com uma certa concepção da personalidade em sintonia com a temporalidade abstrata dos físicos e matemáticos. É a mesma sucessão temporal impregnada da homogeneidade espacial que envolve o estabelecimento de intervalos e a fixação de contornos dos objetos materiais, representada quando contamos os estados de consciência que se sucedem temporalmente e estabelecemos intervalos entre eles, fixando seus contornos. Ou seja, a partir da consideração do tempo como um meio homogêneo (característica de nossa representação espacial), acabamos por tratar os estados de consciência como coisas materiais que ocupam lugar no espaço, isto é, como se eles fossem exteriores uns aos outros. Assim considerado, o tempo psicológico é também representado como "um espaço ideal, onde supomos alinhados todos os acontecimentos passados, presentes e futuros ..." (Bergson, 1993a, p.9). Desse modo, ao introduzir a idéia de espaço em nossas representações da sucessão psicológica, justapondo nossos estados de consciência de maneira a percebê-los simultaneamente um ao lado do outro, concebemos a sucessão, apreendemos nossas modificações internas, sob a forma de uma linha espacial contínua ou de uma cadeia cujas partes se tocam sem se penetrar.

Essa representação espacial da temporalidade psíquica ou, conforme as palavras de Bergson em Introduction à la métaphysique (1993a, p.208) "uma multiplicidade de momentos ligados uns aos outros por uma unidade que os atravessa como um fio", ou seja, uma representação que exprime simultaneamente a multiplicidade e a unidade, coloca-nos diante de concepções antagônicas cuja diferença está na ênfase em um ou outro desses aspectos. Do ponto de vista da multiplicidade, por menor que seja o 
espaço temporal considerado, ele será composto por um número ilimitado de momentos, o que significa que nenhum momento dura, cada um é "instantâneo", o tempo pulveriza-se e o psíquico começaria e recomeçaria a cada instante. Em conseqüência dessa multiplicidade que anula a duração, a própria unidade que liga os momentos não pode durar mais que eles. Essa unidade passa a ser entendida, então, enquanto eternidade, ou seja, uma "essência intemporal do tempo", uma eternidade "abstrata", pois é "vazia"; daí não se compreender como seria possível "que coexistisse com ela uma multiplicidade indefinida de momentos" (Bergson, 1993a, p.209). São duas concepções que misturam "duas abstrações" as quais fixam o fluir do tempo, o escoamento do rio "numa imensa cascata sólida, ou numa infinidade de pontos cristalizados, sempre numa coisa que participa necessariamente da imobilidade de um ponto de vista" (Bergson, 1993a, p.209).

Em decorrência da representação da personalidade como "uma série de estados psicológicos distintos, cada um invariável, que produziriam variações do eu por sua própria sucessão, e por outro lado um eu, não menos invariável, que lhe serviria de suporte" (Bergson, 1993a, p.165), teria surgido o problema de se compreender a união dessa multiplicidade $e$ dessa unidade e a dificuldade de se explicar a constituição de um "eu que dura", já que nenhum desses dois pretensos componentes da personalidade duram: "a mudança é alguma coisa que se acrescenta" ao primeiro, enquanto que o segundo é feito de "elementos que não mudam" (Bergson, 1993a, p.165). Bergson critica essa caracterização da vida interior, refutando a existência de um "substrato rígido imutável" e de "estados distintos que nele passam como atores em uma cena" (Bergson, 1993a, p.165).

Daí resulta que toda tentativa de recomposição da sucessão psicológica pela inteligência é artificial $e$ isso porque, por meio da abstração e da análise, o máximo que se consegue é constituir estados psíquicos mais ou menos independentes, como se eles fossem partes da consciência, como se ela tivesse partes. Seria como tentar reconstituir um poema a partir das letras que entram em sua composição e estão misturadas ao acaso.

\section{Tempo real}

\section{Parte I}

Consideremos agora o tempo real, "o tempo vivido ou que poderia o ser". O tempo de Bergson não é o tempo espacial, esse "vazio" no qual os acontecimentos se sucederiam. O filósofo propõe que desviemos nosso olhar e consideremos os próprios acontecimentos, sejam eles psíquicos ou físicos. É aí que descobriremos o tempo real, cujas propriedades fundamentais são a sucessão, a continuidade, a mudança, a memória e a criação. Embora esses aspectos da duração estejam intimamente relacionados, trataremos cada um deles em separado.

Primeiro, temos como propriedade fundamental do tempo real a sucessão. Ou seja, as vivências interiores, assim como os acontecimentos no mundo físico, embora possam ser simultâneos ou contemporâneos uns dos outros, são também sucessivos, ou seja, ocorrem uns após os outros, constituem uma história. Pensamos no tempo em termos da sucessão passado, presente $e$

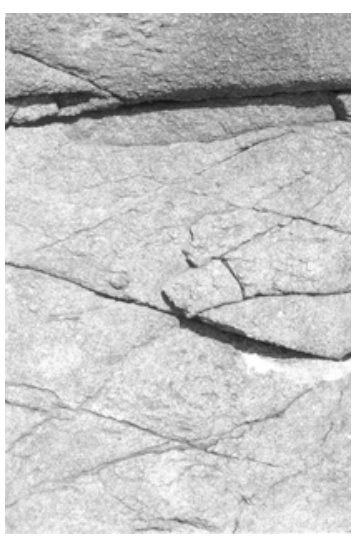


futuro. Consideramos como acontecimentos passados aqueles que antecederam os acontecimentos presentes, não estando mais se realizando; como acontecimentos presentes os que substituem os passados, precedem os futuros e estão ainda se realizando; e como acontecimentos futuros aqueles que substituirão os presentes, que ainda se realizarão.

Segundo, essa sucessão é uma continuidade, ou seja, o tempo é um processo contínuo. Isso significa que os acontecimentos psíquicos ou físicos acontecem uns após os outros, mas não de uma maneira que se assemelhe a uma série numérica espacial. Diferentemente do espaço no qual as partes das coisas podem ser divididas por existirem simultaneamente - pensemos na representação espacial do tempo, uma linha cujos pontos representativos dos instantes são dados simultaneamente - não se pode separar, efetivamente, no real, o presente do passado, isso porque quando focamos um instante presente ele já é passado. Daí não ser possível a medição, considerando-se que a medida implica sobreposição espacial.

Que o deixemos em nós ou que o coloquemos fora de nós, o tempo
que dura não é mensurável. A medida que não é puramente
convencional implica em efeito divisão e superposição. Ora não se
poderia superpor durações sucessivas para verificar se elas são iguais
ou desiguais; por hipótese, uma não é mais quando a outra aparece; a
idéia de igualdade constatável perde aqui toda significação. Por outro
lado, se a duração real torna-se divisível como veremos, pela
solidariedade que se estabelece entre ela e a linha que a simboliza, ela
consiste ela própria em um progresso indivisível e global. (Bergson,
1972, p.102)

Para compreender essa característica da duração, ou seja, de uma sucessão sem separação, Bergson propõe que pensemos numa melodia ouvida, não na melodia representada espacialmente, retendo a continuação do que precede no que se segue, a transição ininterrupta.

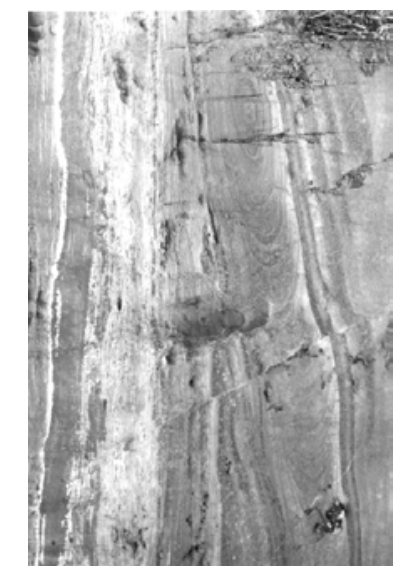

Escute a melodia de olhos fechados, pensando apenas nela, não justapondo mais sobre um papel ou sobre um teclado imaginário as notas que concebeis assim uma pela outra, que aceitam então tornar simultâneas e renunciam à sua continuidade de fluidez no tempo para se congelar no espaço: encontrareis individida, indivisível, a melodia ou a porção da melodia que tiveres recolocado na duração pura. Ora, nossa duração interior, encarada do primeiro ao último momento da vida consciente, é alguma coisa como essa melodia. Nossa atenção pode se desviar dela e conseqüentemente de sua indivisibilidade; mas, quando tentamos a separar, é como se passássemos bruscamente uma lâmina através de uma chama: dividimos apenas o espaço ocupado por ela. Quando assistimos a um movimento muito rápido, como o de uma estrela cadente, distinguimos muito nitidamente a linha de fogo, divisível à vontade, da indivisível mobilidade que ela subentende: é esta mobilidade que é pura duração. (Bergson, 1972, p.102) 
Terceiro, essa continuidade, como o próprio exemplo da melodia indica, é uma continuidade de mudança. Bergson, algumas vezes, define o tempo como uma "continuidade indivisa de mudança heterogênea". A sucessão temporal é uma mudança ou fluxo contínuo incessante, uma transformação ininterrupta. Tanto na vida psíquica quanto no mundo físico, não há estabilidade. Os acontecimentos não são os mesmos, ainda que houvesse repetição, que eu pronunciasse as mesmas palavras de ontem, que resolvesse o mesmo problema da mesma forma, seria a segunda vez e não a primeira, $e$, a rigor, não posso dizer que sou o mesmo ou que o mundo é o mesmo, que haja dois momentos idênticos. A mudança é constitutiva do real, não havendo, assim, uma essência que permaneceria inalterada, uma identidade permanente por trás das mudanças. Segundo Bergson, trata-se

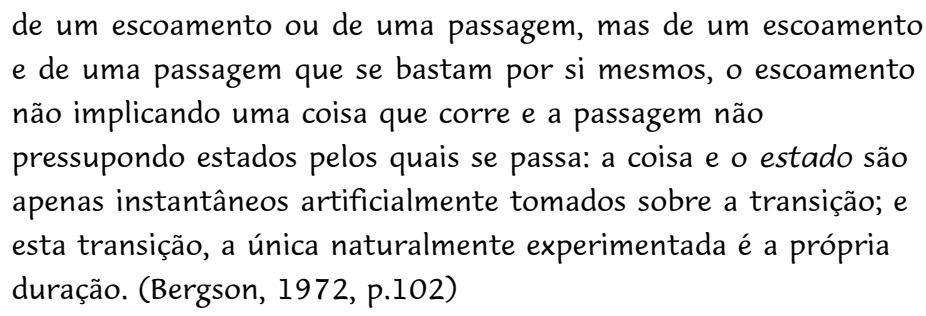

O que acontece é que, freqüentemente, em função das necessidades de nossa existência e da ação, do caráter seletivo de nossa percepão, privilegiamos os aspectos superficiais dos fenômenos observados, as repetições. O que significa afirmar diante do espelho que sou a mesma pessoa de dez anos atrás, ou de ontem ou mesmo de há dez minutos? Segundo Bergson, estamos fechando os olhos à incessante variação constitutiva do real.

Quarto, ao definir a duração como essencialmente uma continuação do que não é mais no que é, Bergson estabelece que a sucessão contínua de mudança heterogenea é memória. A memória é fundamental para a compreensão da relação entre continuidade e mudança.

No âmbito pessoal Bergson destaca dois tipos de memória. Uma é a memória automática ou corporal, ou seja, os hábitos corporais adquiridos pela repetição, como no caso de um verso que aprendemos de cor ou de uma música habilmente tocada em um instrumento, cujos desempenhos independem da atenção consciente. A outra é a memória por imagens, a lembrança consciente de tudo o que vivemos anteriormente e que permanece arquivado em nosso inconsciente. Mas tanto a memória-hábito quanto a memória por imagens, exterior àquilo que ela retém, distinta do passado que ela conserva, são modos de ser da memória bergsoniana que pode ser definida em termos mais gerais como marca do passado no presente, "uma memória interior à própria mudança, memória que prolonga o antes no depois e os impede de serem puros instantâneos aparecendo e desaparecendo em um presente que renasceria incessantemente" (Bergson, 1972, p.101). Em relação a este aspecto, Bergson afirma da duração psicológica o que pode ser estendido às outras durações, ou seja, à história evolutiva dos seres vivos e do próprio universo.

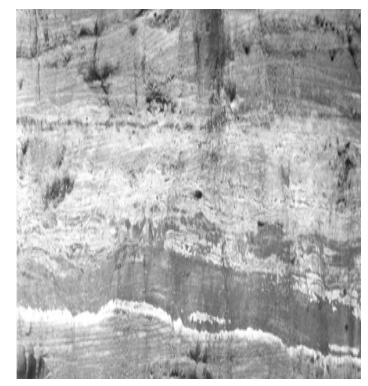




\begin{abstract}
A duração interior é a vida contínua de uma memória que prolonga o passado no presente, seja porque o presente encerra distintamente a imagem incessantemente crescente do passado, seja, mais ainda, porque testemunha a carga sempre mais pesada que arrastamos atrás de nós à medida que envelhecemos. Sem essa sobrevivência do passado no presente, não haveria duração, mas somente instantaneidade. (Bergson, 1993b, p.200)
\end{abstract}

O presente psicológico e físico de uma pessoa, de um grupo social, dos seres vivos e do próprio universo traz a marca dos acontecimentos que lhes precederam, o que permite fazer inferências sobre esses acontecimentos, ainda que em alguns casos remonte a milhões de anos $e$ a rigor não se repitam justamente em função dessas marcas. Só poderia haver repetição, $e$ mesmo assim em termos relativos, se fosse possível abolir a memória, e com isso a história que precede os acontecimentos presentes.

Quinto, o tempo real é criação. A irreversibilidade do tempo, dos acontecimentos, sua riqueza e maior complexidade relacionam-se à memória, mas sua imprevisibilidade deve-se tanto à memória quanto a um dinamismo interno e criador. A memória é importante pois explica, em parte, a relação entre tempo decorrido e aumento de complexidade propiciadora de imprevisibilidade e novidade. Supõe-se, assim, que no âmbito pessoal, por exemplo, quanto mais experiência acumulada maior a possibilidade de criação de novidade. Para Bergson essa relação nem sempre é confirmada pelo fato de a maioria das pessoas terem sua ação regulada pelos hábitos adquiridos e pelas exigências da vida prática.

Para explicar o aspecto dinâmico e criador encontrado em toda parte Bergson acrescenta uma outra noção importante: a noção de élan vital. Embora esta nos remeta imediatamente ao processo evolutivo dos seres vivos tomados individual ou coletivamente, ela pode ser estendida ao universo como um todo. Para Bergson, criação não é escolha entre possíveis pré-estabelecidos, mas é invenção do novo, do que não preexistia a sua realização. Essa dinâmica criadora pode ser observada tanto na história do universo que envolve o percurso de uma estrutura aparentemente simples de matéria condensada ao número gigantesco de diferentes mundos com suas estruturas e modo de funcionamento altamente complexos, quanto na história evolutiva dos seres vivos com suas extraordinárias formas $e$ competências cognitivas e comportamentais, e, ainda, na história humana, com as impressionantes realizações no campo das ciências, das técnicas e das artes.

Daí porque contra toda forma de determinismo, incluindo aí os finalismos - determinismo dos fins -, Bergson entende que o futuro tanto de um sujeito psicológico, quanto das várias formas de vida e, ainda, do

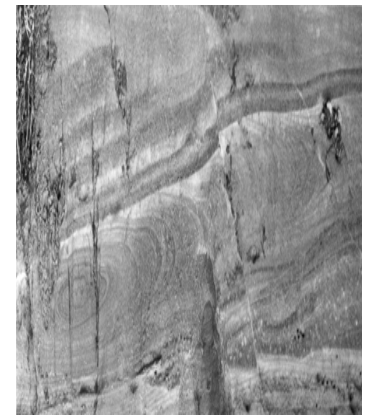
universo como um todo, não poderia ser previsto, não porque nos faltem os meios e conhecimentos intelectuais para tanto, porque não sejamos oniscientes, mas porque em virtude desse dinamismo interno criador ele é em si mesmo indeterminado. Embora a indeterminação possa também estar relacionada à relação entre os seres psíquicos, biológicos e inorgânicos, essa por si só não explicaria a imprevisibilidade, considerando-se que, se fosse o 
COELHO, J. G.

caso, as leis dessa relação poderiam, pelo menos em princípio, ser estabelecidas.

\section{Parte II}

Como Bergson estabelece as propriedades do tempo real a partir da vida interior, ou seja, segundo o modelo da duração psicológica, escolhemos um caso que envolve perturbações psicológicas, embora a causalidade seja orgânica, para ilustrar alguns aspectos da duração bergsoniana. Trata-se da extraordinária história de Jimmie G., narrada pelo neurologista e escritor Oliver Sacks em seu livro $O$ homem que confundiu sua mulher com um chapéu, uma coletânea de casos de doenças neurológicas que afetam principalmente as funções mentais.

Jimmie era portador da síndrome de Korsakov, causada pela destruição alcoólica dos neurônios dos corpos mamilares do cérebro. Tratava-se, portanto, de uma doença cuja causa é física. Sua patologia caracterizava-se por uma devastação grave e permanente da memória, o que incluía a amnésia retrógrada e a perda da memória recente. Korsakov escreveu em 1887:

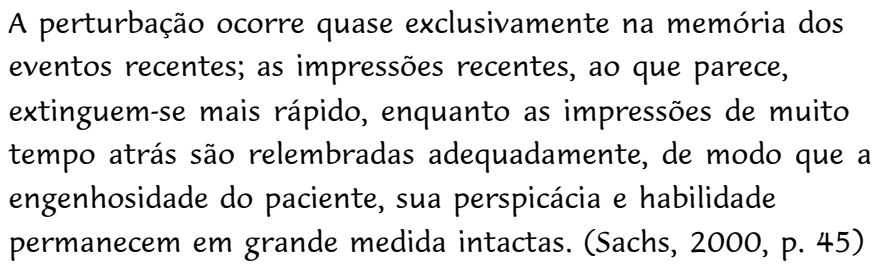

Segundo relato de seu irmão, Jimmie passou a beber demais por volta de 1965, quando saiu da marinha, e ainda mais em 1970, quando, por tornarse excitado e confuso, foi internado no Hospital de Bellevue. Em 1975, com 49 anos de idade, Jimmie não se recordava do que aconteceu após 1945, época em que tinha dezenove anos. Ou seja, a doença apagou trinta anos de sua história.

Desse modo, Jimmie, aos 49 anos, lembrava-se com uma riqueza de detalhes do que vivenciou até os 19 anos, conservando, além dos conhecimentos, as habilidades até então adquiridas. Por exemplo, nos testes de inteligência, demonstrava grande capacidade, era perspicaz, observador e lógico, resolvendo sem dificuldades problemas complexos e quebra-cabeças. Sabia ler, escrever, jogar damas e xadrez. Era excelente em cálculos aritméticos e algébricos. Conhecia os elementos químicos da tabela periódica. Recordava-se de seu irmão.

Tudo a partir dessa idade foi apagado da memória de jimmie. Ao ver seu irmão, embora o reconhecesse, não entendia porque parecia tão velho. Não reconhecia uma fotografia da Terra tirada da Lua, surpreendendo-se ao ser informado de que o homem havia ido à Lua. Não se lembrava de ter visto um porta-aviões, embora tivesse servido na marinha até $1965 \mathrm{em}$ perfeitas condições de saúde. Jimmie afirmava estar em 1945 e ao ser colocado diante de um espelho empalidecia, dizia não saber o que estava acontecendo, se era pesadelo ou loucura, entrando em pânico. Não entendia por que não tinha

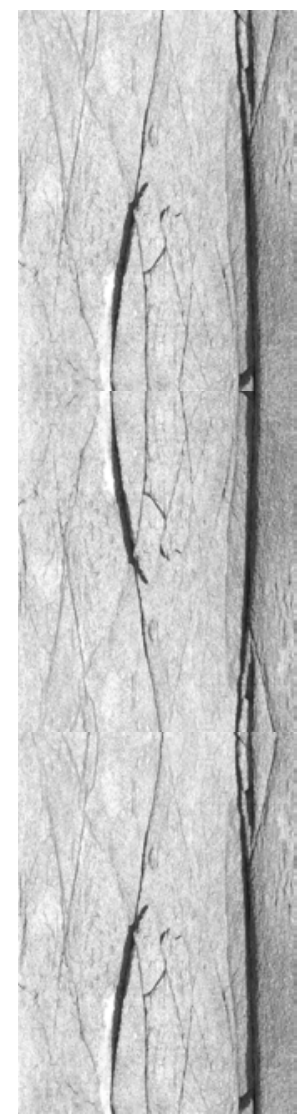


aparência de 19 anos e sim de uma pessoa idosa.

Além dessa forma de amnésia retrógrada, Jimmie sofria uma perda severa da memória recente. Tudo o que lhe era dito ou mostrado tendia a ser esquecido em poucos segundos. Por exemplo, após chocar-se com sua aparência no espelho, bastava levá-lo até a janela para que ele se esquecesse do ocorrido e ficasse tranqüilo. Mas esquecia-se também do médico, demonstrando não conhecê-lo cada vez que o encontrava. Embora convivesse todos os dias com as mesmas pessoas no asilo onde estava internado, parecia não conhecê-las. Resolvia problemas e quebra-cabeças que não exigissem muito tempo, pois esquecia o que estava fazendo. Tinha facilidade nos cálculos, se pudessem ser feitos em velocidade relâmpago, pois se houvesse muitas etapas, tempo demais no processo, ele esquecia onde estava e qual era a questão. Por isso tinha dificuldades para jogar xadrez.

O que essa trágica história de jimmie nos revela sobre a temporalidade psicológica?

A amnésia retrógrada de jimmie mostra a vida como uma sucessão de eventos físicos e psíquicos, uns interferindo com os outros. A sucessão tal como apresentada destaca alguns momentos, ou seja, representa a vida de Jimmie como se fosse uma sucessão numérica na qual os momentos estão separados uns dos outros. Mas, de fato, a sucessão das vivências de Jimmie é contínua, aliás como toda sucessão de acontecimentos físicos e psquícos, $e$ só em pensamento podemos privilegiar e fixar um ou outro dos momentos de sua história. A partir da doença e do conseqüente déficit da memória, as vivências presentes de Jimmie continuam mudando - um fluxo contínuo de mudança heterogênea - umas substituindo as outras, sem que se possa estabelecer o limite entre elas, embora não haja novos aprendizados, enriquecimento de sua vida psicológica.

A história de jimmie mostra ainda que o que somos a cada momento de nossas vidas relaciona-se a essa sucessão de eventos antecedentes. Podemos ir além do que o caso de jimmie ilustra e relacionar a história presente e pessoal de qualquer ser humano não apenas aos eventos de sua história pessoal, mas também do que a antecede, ou seja, a história da cultura na qual ele se insere, da evolução biológica e do próprio universo da qual é herdeiro.

É nesse sentido que Bergson define a duração psicológica como memória. o que vivenciamos desde o nascimento é preservado sob a forma de lembranças e de características adquiridas. Jimmie, fisicamente um homem de 49 anos de idade, após seu déficit de memória que apagou o vivenciado nos trinta anos anteriores, volta a ser psiquicamente o homem que era aos 19 anos. Lembra-se apenas do que aprendeu até essa idade, das pessoas que conheceu, preservando as habilidades que até então havia adquirido. Sendo a memória considerada por Bergson como uma marca do passado no presente, a lembrança é apenas uma dessas marcas, as habilidades aprendidas, as condições corporais, como o envelhecimento, por exemplo, seriam outras dessas marcas. É nesse sentido que se pode afirmar que uma árvore tem memória e que é possível reconstituir sua idade.

A perda da memória recente de jimmie é também muito sugestiva, mostrando que sem memória não há história, não há enriquecimento 
pessoal. Se jimmie vivesse noventa anos, embora seu corpo denunciasse sua idade, memória corporal, psiquicamente ele continuaria sendo o mesmo homem de 19 anos. Todas as suas novas vivências seriam quase que imediatamente esquecidas. O que seríamos se a cada momento nos esquecêssemos de tudo que vivenciamos desde o nosso nascimento? Se não houvesse alguém ou alguma fonte de onde obtivéssemos informações a respeito do passado que antecede ao nosso nascimento?

Podemos ainda refletir a partir do caso de Jimmie sobre um outro aspecto da duração bergsoniana: a criação. Como identificar uma dinâmica criadora, um élan vital, na vida de jimmie? O déficit da memória revela um empobrecimento de sua vida psicológica. Aqui deve-se esclarecer que para Bergson, embora o processo criador possa revelar-se nos indíviduos, ele faz parte efetivamente do mundo considerado enquanto totalidade. O élan vital pode enfrentar obstáculos e operar mais vagarosamente aqui e ali, mas no final das contas acaba prevalecendo. Nossa vida pessoal pode revelar de modo privilegiado essa dinâmica criadora, como a revela num nível mais explícito as criações de artistas e cientistas. Mas ainda que por uma razão ou por outra a criação do novo não se produza aqui e ali, segundo Bergson, ela acabará por se impor, quando se considera o conjunto, seja dos seres humanos, dos seres vivos ou o próprio universo.

\section{Conclusão}

Como vimos, Bergson considera que o tempo não é um vazio homogêneo no qual os acontecimentos se sucederiam semelhante à idéia do espaço vazio no qual os objetos estariam colocados simultaneamente. Ao dizer que o tempo é o tecido do real, Bergson estabelece que o tempo compreendido como sucessão, continuidade, mudança, memória e criação não pode ser separado dos acontecimentos, sejam eles psicológicos ou físicos. Nesse sentido, o tempo é único, ou seja, essa é a natureza da infinidade de fluxos ou durações temporais contemporâneas.

Esse tempo ao qual Bergson atribui uma realidade objetiva é percebido subjetivamente. Dentre os seres existentes, alguns têm o privilégio de perceber conscientemente o tempo, de apreender-se enquanto sujeitos temporais, de perceber imediatamente a duração interior e a partir daí atribuir temporalidade aos acontecimentos externos, contar o tempo das coisas. Consideremos alguns desses aspectos envolvidos em nossa percepção do tempo.

Primeiro, a percepção consciente da temporalidade é possível graças à memória. Se a consciência fosse possível sem a memória, o que não é o caso para Bergson, viveríamos num eterno presente sem as idéias de antes $e$ depois, sucessão, continuação e mudança. É a memória que nos permite estabelecer relação entre as vivências presentes $e$ as anteriores, religar dois instantes um ao outro.

Segundo, é a partir da temporalidade interior que atribuímos temporalidade aos eventos externos. Isso porque a cada momento de nossa vida interior podemos estabelecer correspondência com um momento de nosso corpo e de toda a matéria circundante simultânea e, graças à memória, estabelecer essa mesma correspondência em relação aos eventos 
anteriores.

Por fim, há um componente da experiência psicológica do tempo que também deve ser considerado: freqüentemente, os acontecimentos externos $e$ internos parecem ocorrer de maneira mais ou menos veloz. Para Bergson, a sensação de maior ou menor duração dos eventos físicos ou psíquicos relaciona-se à nossa inserção pragmática no mundo, a qual rege a relação entre os eventos internos e os externos.

Os eventos físicos têm um ritmo que lhes é inerente. Por exemplo, a dissolução do açúcar na água leva um determinado tempo, do mesmo modo que os movimentos de rotação da Terra em torno dela mesma e de translação em torno do Sol. Mas a nossa percepção dessa duração como sendo mais ou menos rápida depende da relação que estabecemos com estes fenômenos em função de nossos interesses da vida prática. Se estamos atentos a todos os detalhes de um acontecimento, ele parece ser mais demorado. Se desviamos nossa atenção, pensando em outra coisa, ele nos parece ocorrer mais rapidamente.

O ritmo dos processos psicológicos varia também em função de nossa relação com os fenômenos externos e da atenção que prestamos a eles. Um exemplo de desatenção mais ampla em relação ao desenrolar dos eventos do mundo é a situação dos sonhos. Durante um sonho de dois minutos, podemos experenciar vivências que necessitariam de muito mais tempo para serem efetivamente experenciadas. Os casos mais extremos de alteração da relação temporal entre o indivíduo e o mundo externo é o de sufocamento brusco, por exemplo, sufocamento ou afogamento. Nesses casos, muitos dos que voltaram à vida declararam "ter visto desfilar diante de si, num tempo muito curto, todos os acontecimentos esquecidos de sua história, com suas mais íntimas circunstâncias e na própria ordem em que se produziram" (Bergson, 1990, p.172).

\section{Referências}

BERGSON, H. Mélanges. Paris: PUF, 1972.

BERGSON, H. Essai sur les données immédiates de la conscience. Paris: PUF, 1988.

BERGSON, H. Matière et Mémoire. Paris: PUF, 1990.

BERGSON, H. L'évolution créatrice. Paris: PUF, 1991.

BERGSON, H. La pensée et le mouvant. Paris: PUF, 1993a.

BERGSON, H. L'énergie spirituelle. Paris: PUF, 1993b.

PIETTRE, B. Filosofia e ciência do tempo. Bauru: Edusc, 1997.

SACHS, O. O homem que confundiu sua mulher com um chapéu. São Paulo: Companhia das Letras, 2000.

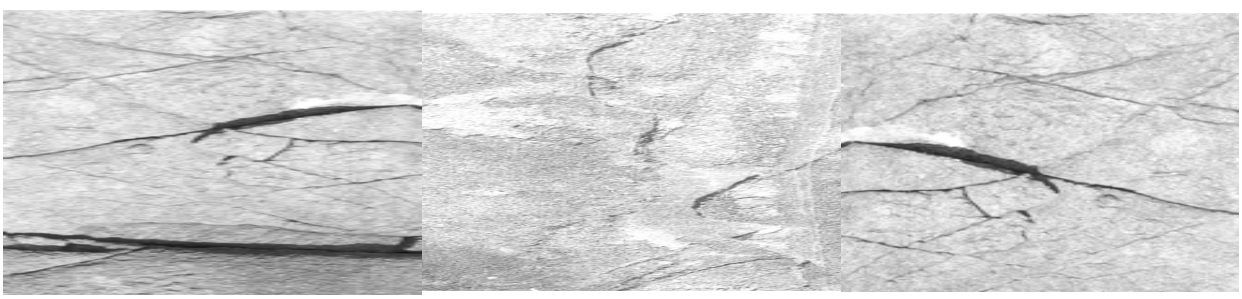

Interface - Comunic., Saúde, Educ., v.8, n.15, p.233-46, mar/ago 2004 
COELHO, J. G.
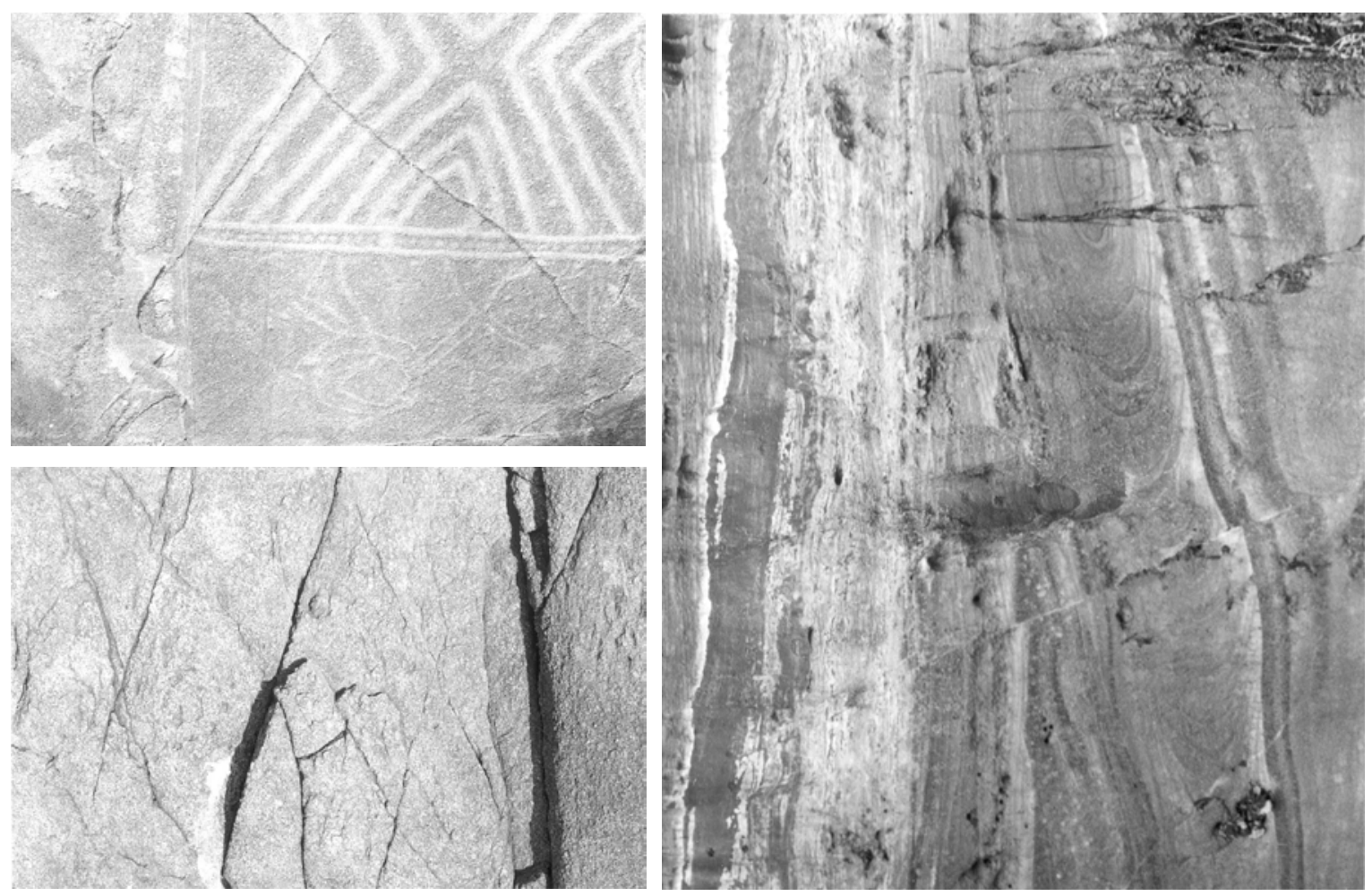

ELISETE ALVARENGA, Marcas, 2002

COELHO, J. G. Ser del tiempo en Bergson, Interface - Comunic., Saúde, Educ., v.8, n.15, p.233-46, mar/ago 2004.

El presente artículo trata de la concepción bergsoniana de duración. Pretendemos mostrar que, según Bergson, el tiempo de los filósofos y científicos es un tiempo ficticio, un esquema espacial que oculta la naturaleza del tiempo real, el cual no puede ser separado de los acontecimientos físicos y psicológicos. Para Bergson, el tiempo real es sucesión, continuidad, cambio, memoria y creación.

PALABRAS CLAVE: Bergson; duración; tiempo; espacio. 